\title{
Retention of Rice dwarf virus by Descendants of Pairs of Viruliferous Vector Insects After Rearing for 6 Years
}

\author{
Kazuto Honda, Taiyun Wei, Kyoji Hagiwara, Takahiko Higashi, Ikuo Kimura, Katsumi Akutsu, and Toshihiro Omura
}

First, second, third, fourth, fifth, and seventh authors: National Agricultural Research Center, Tsukuba, Ibaraki 305-8666, Japan; first and sixth authors: Faculty of Agriculture, Ibaraki University, Ami, Ibaraki 300-0332, Japan.

Accepted for publication 9 January 2007.

\begin{abstract}
Honda, K., Wei, T., Hagiwara, K., Higashi, T., Kimura, I., Akutsu, K., and Omura, T. 2007. Retention of Rice dwarf virus by descendants of pairs of viruliferous vector insects after rearing for 6 years. Phytopathology 97:712-716.

Rice dwarf virus (RDV) is characterized by its unusual ability to multiply in both plants and leafhopper vector insects and by its transovarial mode of transmission. Colonies of Nephotettix cincticeps, derived originally from pairs of leafhoppers infected with an ordinary strain of RDV, were maintained for 6 years in the laboratory and were found, at the end of this time, still to harbor RDV. Moreover, the isolate of RDV, designated RDV-I, obtained from these colonies retained the ability to infect rice

in the presence of healthy rice seedlings, we found that all of these leafhoppers harbored RDV. This observation suggested that RDV-I had been maintained in the leafhoppers by transovarial transmission. Two further observations, namely, the low rate of acquisition of RDV by virus-free insect nymphs on symptomless plants on which viruliferous insects had been reared, and the fact that only 2 to $5 \%$ of plants had symptoms when rice seedlings were inoculated via RDV-I-viruliferous insects, confirmed that the maintenance of RDV-I by any other mode of transmission through plants and insects was unlikely. This efficient and long-term maintenance of RDV in a population of viruliferous insects might explain the prolonged duration of rice dwarf disease in the field, once there has been a serious outbreak.
\end{abstract} plants. When we raised leafhoppers separately from eggs that had been placed individually on pieces of water-soaked filter paper and reared them
Additional keyword: Phytoreovirus.
Rice dwarf virus (RDV), the causative agent of a serious disease in rice in northeastern Asia, belongs to the genus Phytoreovirus in the family Reoviridae $(2,11)$. The green rice leafhopper Nephotettix cincticeps acquires the virus by feeding on RDV-infected rice plants for a few minutes to several days. The virus proliferates in the leafhopper vector and the insect becomes RDV infective after a latent period of 2 to 3 weeks. Infections due to RDV have become endemic and, once serious infection has occurred in the field, it can last for several years (10). After harvest, RDV-infected rice sprouts are unable to survive the winter in northern Asia and, thus, survival in the insect host or in the alternative plant host (2) are considered to be possible reasons for the prolonged duration of the disease.

Transovarial transmission of a plant virus by its insect vector was first described for RDV by Fukushi (4) and this phenomenon has been reported for Wound tumor virus (WTV) (1), Rice gall dwarf virus (12), and Nilaparvata lugens reovirus (19) among viruses in the family Reoviridae. The extent of maintenance of RDV in viruliferous insects by transovarial transmission remains to be clarified because, in the early study by Fukushi (6), for example, viruliferous females were selected arbitrarily and used in each generation, and many of the insects lost infectivity over time. Subsequently, transovarial passage was reported for several viruses in their leafhopper or planthopper $(1,9)$, aphid $(24)$, and whitefly (8) vectors. Transovarial transmission often has been found to be associated with replication of the virus in its vector $(1,3,5,16)$ and, usually, the virus is transmitted to some but not all progeny (4 to $95 \%$ ).

In the present study, we maintained the descendants of pairs of viruliferous vector insects for several years without any specific

Corresponding author: T. Omura; E-mail address: toomura@affrc.go.jp

doi:10.1094/PHYTO-97-6-0712

(C) 2007 The American Phytopathological Society treatment and examined the persistence of RDV in such insects. We also examined whether the viruses detected in descendants retained infectivity to rice plants and found that they caused RDV disease in plants. We determined that all $(100 \%)$ of the descendants of viruliferous pairs of insects retained RDV that had been inherited by transovarial transmission, even after 6 years and 54 generations.

\section{MATERIALS AND METHODS}

Viruses. Young instar nymphs of $N$. cincticeps were allowed 2 days of acquisition access feeding on rice plants that previously had been infected with an ordinary strain of RDV (RDV-O) (14). Then, the leafhoppers were reared on healthy rice seedlings (cv. Koshihikari) for 20 days at $25 \pm 3^{\circ} \mathrm{C}$. Pairs consisting of one female and one male leafhopper were selected and confined, for oviposition, with single rice seedlings in glass tubes $\left(1.5 \mathrm{~cm}^{2}\right.$ by $15 \mathrm{~cm}$ ) for 7 days at $26 \pm 1^{\circ} \mathrm{C}$ under continuous fluorescent light in an insect-rearing room. After confinement in tubes, leafhoppers were tested individually for viral infection by an enzyme-linked immunosorbent assay (ELISA) (25).

Rice seedlings, with eggs, in the glass tubes that had harbored pairs of leafhoppers that yielded positive results in the ELISA were incubated in the insect-rearing room, as described above, until the emergence of leafhopper progeny. The offspring of each pair of leafhoppers separately were collected and maintained in cages of $\approx 20$ by 30 by $25 \mathrm{~cm}^{3}$, with changes of rice seedlings at intervals of 8 to 10 days, in the insect-rearing room. The duration of the life cycle of the leafhopper under our conditions was $\approx 40$ days. The RDV-carrying population of leafhoppers that had been obtained in this way was maintained for 6 years. The RDV maintained in this population was designated insect isolate of RDV (RDV-I). We used a total of three similarly generated populations in our study of RDV transmission. 
Electron microscopy. Hemolymph from adult insects was dropped onto grids, stained with uranyl acetate, and observed under an electron microscope (H-7000; Hitachi, Japan). Immunogold staining of viral particles was performed with RDV-specific antibodies (25), as described elsewhere (15).

Transovarial transmission. Female adults from RDV-Iharboring populations were confined individually with rice seedlings for oviposition. Eggs were removed from the seedlings and placed individually on pieces of water-soaked filter paper. Pieces of filter paper with individual eggs were placed separately in glass tubes $\left(1.5 \mathrm{~cm}^{2}\right.$ by $\left.15 \mathrm{~cm}\right)$ with healthy rice seedlings. Offspring were tested individually for the presence of RDV by the ELISA at the nymph or adult stage. Values in the ELISA of absorbance at $405 \mathrm{~nm}$ that were more than four times higher than values from healthy controls were regarded as positive results, because the ELISA values for viruliferous insects and healthy controls were very clearly distinguishable.

As one set of controls for comparisons, we released virus-free adult insects on RDV-infected rice plants with symptoms and allowed the adults to lay eggs. We reared hatched insect nymphs on the diseased plants and then examined the resultant adult insects for the presence of RDV by ELISA.

Acquisition of RDV by virus-free insect nymphs from symptomless plants on which viruliferous adult insects had been reared. We performed the following experiments to examine the unlikely possibility that RDV might have been maintained by lateral transmission via infected plants to vector insects. We placed virus-free female insects in glass tubes with individual healthy rice seedlings for 5 days so that females could lay eggs. After the removal of the virus-free mother insects, we reared single viruliferous male insects, in whom we subsequently examined the presence of RDV by ELISA, on the same plants in the glass tubes until the death of each male. We examined whether the newly hatched virus-free nymphs acquired RDV that might have been introduced into the plant by viruliferous male insects. Viral infection of the plants was monitored in terms of the appearance of symptoms 20 days after the introduction of the viruliferous male insects. For detection of viral antigens in plants with and without symptoms, we homogenized fresh rice leaves $(0.1 \mathrm{~g})$ with $0.9 \mathrm{ml}$ of a 0.1-M solution of histidine that contained $0.01 \mathrm{M} \mathrm{MgCl}_{2}$ at pH 6.2 (His-Mg solution) with a mortar and pestle. Each homogenate was subjected to serial twofold dilutions with His-Mg solution and subjected to the ELISA.

Transmission directly to rice plants of RDV-I that had been maintained in insects. For inoculation of rice seedlings with RDV-I that had been maintained in insect vectors, we allowed individual adult leafhoppers from populations that had been maintained for more than 4 years a 2-day inoculation access feeding on rice seedlings in individual test tubes. The plants that developed from these seedlings were grown in an air-conditioned greenhouse and monitored for symptoms after 40 days.

Transmission of RDV-I from infected plants to healthy rice plants via virus-free insects. For the transmission of RDV from infected plants to rice seedlings, we allowed second- to third- instar nymphs from a virus-free population of $N$. cincticeps to feed for 2 days on plants that had been infected with RDV-I, RDV-O, or the severe strain of RDV (RDV-S) (14). Leafhoppers then were reared for 20 days, the latent period for the development of RDV infection, on healthy rice seedlings with occasional replacement of seedlings by fresh seedlings. Individual adult viruliferous insects that matured during this 20-day period then were exposed to healthy rice seedlings in individual test tubes for a 2-day inoculation access feeding.

Leafhoppers after inoculation tests were analyzed individually for the presence of viral antigens by the ELISA. When the absorbance at $405 \mathrm{~nm}$ was at least four times higher than that of healthy controls, the leafhopper was regarded as infected. Inoculated seedlings were grown in a greenhouse $\left(25 \pm 3^{\circ} \mathrm{C}\right)$ for 40 days to allow the development of symptoms of infection.

Analysis of segments of genomic RNA. RNA was released from purified viruses by adding sodium dodecyl sulfate (SDS) to $1 \%$ and EDTA to $0.1 \%$ to suspensions of viruses. Then the RNA was subjected directly to SDS-polyacrylamide gel electrophoresis (PAGE) (10\% polyacrylamide). Electrophoresis and staining of nucleic acids were performed as described by Omura et al. (20).

\section{RESULTS}

Detection of viruses in insects that harbored RDV-I. Three populations of leafhoppers, derived from three pairs of male and female viruliferous insects and maintained in cages for more than 4 years, were examined to determine the presence or absence of RDV in individual insects by ELISA. We found that all of more than 60 insects in each of the three populations had retained RDV. We repeated our analysis very carefully to confirm that the material from individual insects that reacted positively in the ELISA was RDV. We performed numerous experiments with large numbers of positive and negative controls and, again, all of 100 tested leafhoppers in each of the three populations gave positive results in the ELISA (data not shown). By contrast, more than 50 insects that had not been exposed to RDV in three replicates gave clear negative results.

Electron microscopy revealed large numbers of spherical particles of $\approx 70 \mathrm{~nm}$ in diameter, which resembled typical RDV particles (17), in all of more than 10 insects examined in each of the three populations (data not shown). Such particles were specifically labeled with gold particles after immunogold staining with RDV-specific antibodies (data not shown).

Transovarial transmission. In three independent experiments, all of 48 second- to third-instar nymphs and 100 adult leafhoppers, generated separately from eggs of RDV-I-viruliferous populations, gave positive results in the ELISA (Table 1). As one set of the controls in this assay, we analyzed the progeny of virus-free insects grown from eggs laid on RDV-infected plants by ELISA. As shown on the last line in Table 1, not all insects grown on plants that had symptoms typical of infection by RDV acquired RDV (94 to $98 \%$ ).

TABLE 1. Transovarial transmission of Rice dwarf virus (RDV)-I to progeny by RDV-I-viruliferous insects, as revealed by an enzyme-linked immunosorbent assay (ELISA) ${ }^{\mathrm{a}}$

\begin{tabular}{|c|c|c|c|}
\hline \multirow[b]{2}{*}{ Insect population } & \multicolumn{3}{|c|}{ Experiment no. ${ }^{b}$} \\
\hline & I & II & III \\
\hline Second- to fourth-instar nymphs of RDV-I-harboring insects & $48 / 48$ & $48 / 48$ & $48 / 48$ \\
\hline RDV-I-harboring adult insects & $100 / 100$ & $100 / 100$ & $100 / 100$ \\
\hline Negative controls ${ }^{c}$ & $0 / 12$ & $0 / 12$ & $0 / 12$ \\
\hline Controls ${ }^{\mathrm{d}}$ & $98 / 100$ & $94 / 100$ & $96 / 100$ \\
\hline
\end{tabular}

\footnotetext{
a Each RDV-I-viruliferous population was tested after six years.

${ }^{b}$ Number of progeny that gave a positive result in the ELISA/number of progeny tested.

c Progeny of virus-free insects grown on healthy rice plants.

d Progeny of virus-free insects grown from eggs on RDV-infected rice plants.
} 
TABLE 2. Acquisition of Rice dwarf virus (RDV) by virus-free insects from symptomless plants on which viruliferous adult insects had been reared ${ }^{\mathrm{a}}$

\begin{tabular}{lcc}
\hline Symptoms & $\begin{array}{c}\text { Viral titer, as detected } \\
\text { by ELISA }^{b}\end{array}$ & $\begin{array}{c}\text { No. of positive insects detected by } \\
\text { ELISA/no. insects tested }\end{array}$ \\
\hline- & $<10$ & $0 / 2$ \\
- & $<10$ & $0 / 3$ \\
- & $<10$ & $0 / 3$ \\
- & $<10$ & $0 / 4$ \\
- & $<10$ & $0 / 5$ \\
- & $<10$ & $0 / 5$ \\
- & $<10$ & $0 / 5$ \\
- & $<10$ & $0 / 5$ \\
- & $<10$ & $1 / 4$ \\
- & $<10$ & $1 / 4$ \\
+ & 40,960 & $2 / 3$ \\
+ & 40,960 & $3 / 4$ \\
+ & 40,960 & $4 / 4$ \\
\hline
\end{tabular}

a Virus-free offspring were grown from eggs laid by virus-free females on healthy plants. Single, viruliferous male insects were reared until death after they had replaced the virus-free females that laid eggs on each plant.

b Values are reciprocals of the dilution end-point of positive results in the enzyme-linked immunosorbent assay (ELISA).

Acquisition of RDV from symptomless plants on which viruliferous insects had been released. To determine whether RDV-I introduced into healthy rice plants by viruliferous insects can be acquired by newly hatched virus-free insect nymphs, we placed a single viruliferous male insect on each rice seedling on which eggs from a virus-free female had been laid. The design of this study was based on the fact that, in a previous study, not all the plants onto which viruliferous insects had been released were infected by RDV (21). We studied acquisition of the virus by ELISA using adult insects grown from eggs on symptomless plants on which viruliferous adult insects had been reared. In all but two cases, the adult insects did not acquire RDV (Table 2). By contrast, $\approx 80 \%$ of the insects grown on plants with symptoms due to direct infection of the plant by a viruliferous male were ELISA positive.

Macerates of plants with symptoms, after inoculation access by insects with RDV, reacted in the ELISA at dilutions of up to 40,960-fold. By contrast, macerates of plants without symptoms yielded negative results for detection of RDV antigens even at 10fold dilution.

Transmission directly to rice plants of RDV-I that had been maintained in insects. We performed a viral transmission study using more than 100 insects that harbored RDV-I from each of three different populations. Some of the plants (4 to $8 \%$ ) had symptoms typical of RDV infection, being stunted with many small chlorotic spots on their leaves, in four replicate experiments (data not shown).

Rice plants infected with RDV-I were more severely stunted than plants infected with RDV-O, the original strain (Fig. 1). Plants infected with RDV-S were most severely stunted. These differences, in terms of plant height, among plants infected with the two different strains and the isolate were consistent for three insect populations in the fourth, fifth, and sixth year of the study.

Transmission of RDV-I from infected plants to healthy rice plants via virus-free insects. We tested leafhoppers that had been allowed acquisition access feeding on rice plants that had been infected with RDV-I, RDV-O, or RDV-S to determine the percentages of carriers and transmitters of each virus. RDV-I was acquired and transmitted to rice plants; however, rates of both acquisition and transmission were lower than those for RDV-O and RDV-S (Table 3). In control tests, none of the leafhoppers that had been allowed acquisition access feeding on healthy rice plants gave a positive result in the ELISA and all failed to transmit RDV.

Detection of RDV-specific double-stranded RNA. Analysis by SDS-PAGE of the nucleic acid released from purified RDV-I

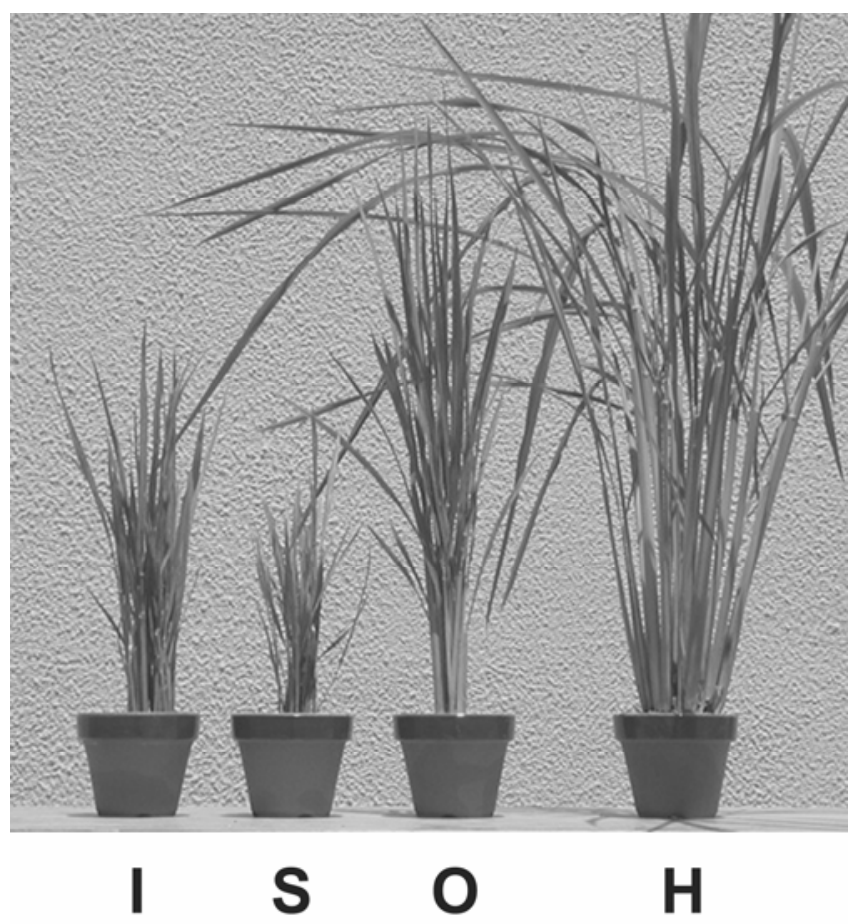

Fig. 1. Rice plants 60 days after inoculation, by virally infected insect vectors, with Rice dwarf virus (RDV)-I (I), RDV-S (S), RDV-O (O), and a healthy control $(\mathrm{H})$.

yielded all 12 of the expected double-stranded RNAs. However, the mobility of one of the segments in three tested isolates was slightly different from that of the same segment of the original strain; nevertheless, it was within the range for RDV mutants (data not shown).

Concentrations of viruses in infected plants. We determined the relative concentrations of viruses in 10 replicate analyses, 40 days after inoculation of plants, by the ELISA, using purified RDV as the standard. We obtained the following results: RDV-I versus $\mathrm{RDV}-\mathrm{O}=0.52 \pm 0.15$ and $\mathrm{RDV}-\mathrm{S}$ versus $\mathrm{RDV}-\mathrm{O}=1.91 \pm$ 0.40 .

\section{DISCUSSION}

We were somewhat surprised that all the insects in our repeated preliminary experiments, with at least 60 insects from each of three lines of insects with RDV-I, yielded positive results in the ELISA. An early report showed that RDV was transmitted up to the seventh generation via the eggs of vector insects (6), but the insects used in this early study were selected as virus-positive in each respective generation of the populations examined, in which not all the insects transmitted the virus. Therefore, we examined very carefully whether the material in the individual insects that reacted positively in the ELISA was actually RDV, in repeated studies with large numbers of positive and negative controls. We found that the immunoreaction was, indeed, specific to RDV. We also analyzed the presence of RDV particles in individual insects by electron microscopy and found many spherical particles, of $\approx 70 \mathrm{~nm}$ in diameter, that were not found in insects that had not been exposed to RDV. Furthermore, these particles reacted positively in immunogold staining with RDV-specific antibodies, confirming that the material that was immunoreactive in the ELISA was RDV. The induction of symptoms specific to RDV infection, even though symptoms were more severe and the percentage of transmitters was lower, as well as a nucleic acid-migration pattern during SDS-PAGE that was typical of RDV, supported the results obtained by the ELISA and our conclusion that it was, 


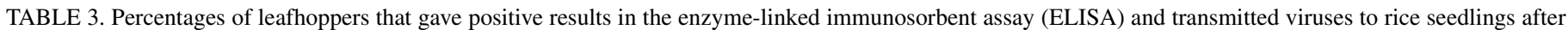
acquisition access feeding on rice plants that had been infected with Rice dwarf virus (RDV)-I, RDV-O, or RDV-S

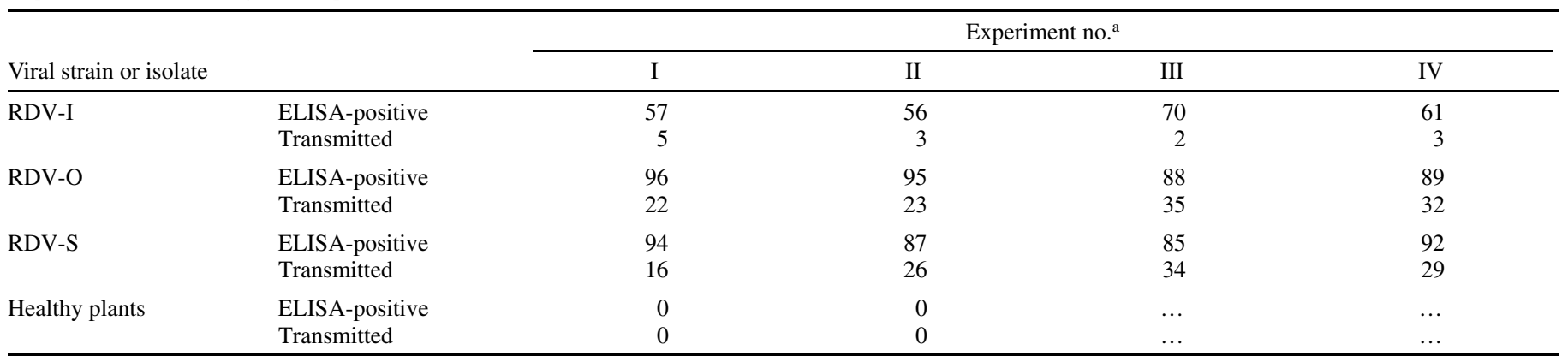

a Number of leafhoppers from among the 100 leafhoppers tested. For RDV-I, results from experiments I through III were obtained from three different populations. Experiment IV was an independent study performed with the same insect colony as that used in experiment I.

indeed, RDV that had been maintained for such a long period of time in populations of the insect vector.

In WTV-infected monolayers of vector cells maintained for a long period of time with repeated passaging, the synthesis of viral polypeptides declined considerably, perhaps because of a change in the translational activity of viral transcripts $(22,23)$. In the current study, the greater stunting of plant growth, compared with that of plants infected with the original standard strain, RDV-O (Fig. 1), was consistent for 60 sets of RDV-I-, RDV-O-, and RDV$\mathrm{S}$-infected plants for the duration of the experiment. These results suggest the possibility that we might have selected a specific isolate, such as RDV-I, which was better adapted to infection of the insect rather than the plant, during the course of specific viral maintenance procedures. The concentration of RDV in plants infected with RDV-I was approximately half of that of RDV in RDV-O-infected plants, and approximately one-quarter of that in RDV-S-infected plants. This lower concentration of viral particles might explain the lower rate of acquisition access feeding on plants infected with RDV-I (Table 3).

Our study of transovarial transmission indicated that $100 \%$ of the insect eggs analyzed harbored RDV (Table 1). By contrast, not all the insects that grew on RDV-infected rice plants on which eggs had been laid by virus-free insects harbored RDV (Table 1). This result indicates that not all virus-free insects acquire RDV even when they are grown from eggs on infected rice plants, and it supports the hypothesis that the presence of RDV-I in all the vector insects in our analysis of descendants of original populations was due to transovarial transmission and not to new acquisition from infected plants. The very low frequency of acquisition of RDV by virus-free insect nymphs on symptomless rice plants on which viruliferous insects had been reared (Table 2), together with the fact that only 2 to $5 \%$ of plants had symptoms (95 to $98 \%$ of plants were symptomless) (Table 3), further supports the hypothesis that RDV was maintained, perhaps exclusively, by transovarial passage for 6 years, and not through lateral transmission via infected plants.

Serious infections of rice plants in the field last for several years (10). The present study shows that RDV might be maintained, in such cases, via vector insects and, probably, by transovarial transmission, so long as a favorable environment supports the high affinity of the virus for the insect vector. Thus, extensive control of leafhopper vectors (for example, with insecticide) is important for rapid termination of epidemics in seriously infected areas. Our screening for cultivars of rice that might be resistant to RDV infection among rice cultivars collected by the Gene Bank of MAFF, Japan, has failed, so far, to identify any RDV-resistant cultivars. However, there are reports of some cultivars of rice that are resistant to the insect vector $N$. cincticeps and, thus, also are resistant to RDV infection (7). The present study suggests the possibility that the use of rice cultivars that are resistant to leafhoppers might contribute to a decrease in the size of the insect population, which eventually would decrease the size of the population of viruliferous insects in areas heavily infected with RDV. This strategy might contribute to stemming outbreaks of rice dwarf disease.

RDV proliferates in both plants and insects. This property of RDV allows the maintenance of viral populations by alternating passages through rice plants and vector insects. RDV loses its affinity for leafhopper vectors when it lacks the P2 outer capsid protein, which is required for adsorption to and penetration by the virus of insect vector cells when the virus is maintained in infected rice plants without passage through vector leafhoppers $(2,13,26)$. In the present experiments, RDV-I was maintained in leafhopper populations and was transmitted actively to rice plants, although the affinity for rice plants decreased. RDV is not transmitted through rice seed (11). Furthermore, RDV is not transmissible mechanically and requires leafhoppers as vectors for the infection of rice plants. Thus, RDV cannot survive in nature in the absence of vector insects. As Nault and Ammar (18) noted, rice plants are "dead-end" hosts for such viruses. However, in our experiments, RDV was maintained continuously for more than 6 years in leafhoppers. These observations suggest that RDV originally might have been an insect virus that acquired the ability to infect plants, rather than a plant virus that acquired the ability to infect insects.

\section{ACKNOWLEDGMENTS}

This study was supported by a Grant-in-Aid for Scientific Research (B) (no. 15380038) from the Japan Society for the Promotion of Science. We thank H. Hibino, I. Fujisawa, and K. Honda for constructive discussions and suggestions related to this study; and $\mathrm{H}$. Takeuchi for supplying vector insects.

\section{LITERATURE CITED}

1. Black, L. M. 1953. Occasional transmission of some plant viruses through the eggs of their insect vectors. Phytopathology 43:9-10.

2. Boccardo, G., and Milne, R. G. 1984. Plant reovirus group. CMI/AAB Description of Plant Viruses, no. 294. Commonwealth Mycology Institute and Association of Applied Biology, Kew, UK.

3. Duffus, J. E. 1963. Possible multiplication in the aphid vector of sowthistle yellow vein virus, a virus with an extremely long insect latent period. Virology 21:194-202.

4. Fukushi, T. 1933. Transmission of the virus through the eggs of an insect vector. Proc. Imp. Acad. (Tokyo) 9:457-460.

5. Fukushi, T. 1935. Multiplication of virus in its vector. Proc. Imp. Acad. (Tokyo) 11:301-303.

6. Fukushi, T. 1939. Retention of virus by its insect vectors through several generations. Proc. Imp. Acad. (Tokyo) 15:142-145.

7. Fukuta, Y., Tamura, K., Hirae, M., and Oya, S. 1998. Genetic analysis of resistance to green rice leafhopper (Nephotettix cincticeps UHLER) in rice parental line, Norin-PL6, using RFLP markers. Breed. Sci. 48:243249.

8. Ghanim, M., Morin, S., Zeidan, M., and Czosnek, H. 1998. Evidence for 
transovarial transmission of tomato yellow leaf curl virus by its vector, the whitefly Bemisia tabaci. Virology 240:295-303.

9. Grylls, N. E. 1954. Rugose leaf curl-a new virus disease transovarially transmitted by the leafhopper Austroagallia torrida. Aust. J. Biol. Sci. 7:47-58.

10. Hibino, H. 1996. Biology and epidemiology of rice viruses. Annu. Rev. Phytopathol. 34:249-274.

11. Iida, T. T., Shinkai, A., and Kimura, I. 1972. Rice dwarf virus. CMI/AAB Description of Plant Viruses, no. 102. Commonwealth Mycology Institute and Association of Applied Biology, Kew, UK.

12. Inoue, H., and Omura, T. 1982. Transmission of rice gall dwarf virus by the green rice leafhopper. Plant Dis. 66:57-59.

13. Kimura, I. 1976. Loss of vector-transmissibility in an isolate of rice dwarf virus. Ann. Phytopathol. Soc. Jpn. 42:322-324

14. Kimura, I., Minobe, Y., and Omura, T. 1987. Changes in a nucleic acid and a protein component of rice dwarf virus particle associated with an increase in symptom severity. J. Gen. Virol. 68:3211-3215.

15. Lin, N. S. 1984. Gold-IgG complexes improve the detection and identification of viruses in leaf dip preparation. J. Virol. Methods 8:181190.

16. Miyamoto, S., and Miyamoto, Y.1966. Notes on aphid-transmission of potato leafroll virus. Sci. Rep. Hyogo Univ. Agric. 7:51-56.

17. Miyazaki, N., Hagiwara, K., Naitow, H., Higashi, T., Cheng, R. H., Tsukihara, T., Nakagawa, A., and Omura, T. 2005. Transcapsidation and conserved interactions of two major structural proteins of a pair of phytoreoviruses confirm the mechanism of assembly of the outer capsid layer. J. Mol. Biol. 345:229-237.

18. Nault, L. R., and Ammar, E. D. 1989. Leafhopper and planthopper transmission of plant viruses. Annu. Rev. Entomol. 34:503-529.

19. Noda, H., Ishikawa, K., Hibino, H., and Omura, T. 1991. A reovirus in the brown planthopper, Nilaparvata lugens . J. Gen. Virol. 72:2425-2430.

20. Omura, T., Minobe, Y., Matsuoka, M., Nozu, Y., Tuchizaki, T., and Saito, Y. 1985. Location of structural proteins in particles of rice gall dwarf virus. J. Gen. Virol. 66:811-815.

21. Omura, T., and Yan, J. 1999. Role of outer capsid proteins in transmission of phytoreovirus by insect vectors. Adv. Virus Res. 54:15-43.

22. Peterson, A. J., and Nuss. D. L. 1985. Wound tumor virus polypeptide synthesis in productive noncytopathic infection of cultured insect vector cells. J. Virol. 56:620-624.

23. Peterson, A. J., and Nuss. D. L. 1986. Regulation of expression of the Wound tumor virus genome in persistently infected vector cells is related to change in translational activity of viral transcripts. J. Virol. 59:195-202.

24. Sylvester, E. S. 1969. Evidence of transovarial passage of the sowthistle yellow vein virus in the aphid Hyperomyzus lactucae. Virology 38:440446.

25. Takahashi, Y., Omura, T., Shohara, K., and Tshchizaki, T. 1991. Comparison of four serological methods for practical detection of ten viruses of rice in plants and insects. Plant Dis. 75:458-461.

26. Tomaru, M., Maruyama, W., Kikuchi, A., J , Yan. J., Zhu, Y. J ., Suzuki, N., Isogai, M., Kimura, I., and Omura, T. 1997. The loss of outer capsid protein $\mathrm{P} 2$ results in nontransmissibility by the insect vector of rice dwarf phytoreovirus. J. Virol. 71:8019-8023. 